\title{
Factors associated with tobacco smoking among Saudi college students: A systematic review
}

\author{
Saad A. Alotaibi ${ }^{1,2}$, Praveen K. Durgampudi
}

\begin{abstract}
INTRODUCTION There has been an increase in tobacco smoking among Saudi college students in recent years. However, no study has examined, with a systematic approach, the extent to which specific factors are associated with tobacco smoking among this population.

Methods PubMed, ProQuest, CINAHL, and Web of Science were utilized to retrieve studies addressing risk factors associated with tobacco smoking among Saudi college students between 2010 and 2019. After confirming their eligibility criteria, studies were imported to the NVivo software for data collection and synthesis. All included articles were critically appraised, based on a modified STROBE.

RESULTS Twenty-one out of 300 studies met the eligibility requirements for inclusion. Riyadh was the location, health-related science was the field of study, and male the gender of the population of most of the included studies. Only one study used a longitudinal design based on a theoretical framework, the rest were cross-sectional and lacked theoretical utilization. Four individual and two social factors were established to have a significant relationship with tobacco smoking behavior among college students in four or more studies. Environmental factors were found to be associated with a change in smoking behavior among Saudi college students based on two studies.

CONCLUSIONS There is a dearth of research in utilizing theoretical frameworks to guide the research in order to propose an intervention program among Saudi college students. Future research should aim to recruit participants from different institutions in the Kingdom of Saudi Arabia (KSA), apply other methodological approaches, test other measurements of tobacco smoking, and utilize a theoretical framework.
\end{abstract}

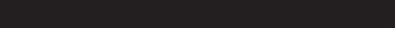 \\ AFFILIATION \\ 1 College of Health Sciences, Old Dominion University, Norfolk, United States \\ 2 College of Applied Medical Sciences, Qassim University, Buraydah, Saudi Arabia \\ CORRESPONDENCE TO \\ Saad A. Alotaibi. College of Health Sciences, Old Dominion University, Norfolk, VA 23529, United States. \\ E-mail: salot001@odu.edu \\ KEYWORDS \\ risk factors, systematic review, tobacco smoking, Saudi Arabia, college students, KSA}

Received: 24 December 2019 Revised: 12 March 2020

Accepted: 14 May 2020

\section{INTRODUCTION}

Tobacco consumption remains one of the most significant public health issues causing deaths, disease, and economic burdens ${ }^{1}$. Although in the United States tobacco smoking rates dropped by $5.4 \%$ in 2016 compared to the prevalence rate in $2005^{2}$, many developing countries such as the Kingdom of Saudi Arabia (KSA) are experiencing an alarming increase in tobacco smoking among their populations ${ }^{3-5}$. AlBedah and Khalil5 reported that the KSA has lost
0.28 million lives and 20.5 billion US dollars due to tobacco smoking between 2001 and 2010, without accounting for smuggled tobacco.

Despite the tremendous efforts that the KSA is making to combat tobacco smoking ${ }^{4}$, researchers have conceded that the prevalence of tobacco smoking is alarming and warrants immediate actions from both Saudi policymakers and health professionals ${ }^{3,5,6}$. For instance, two national surveys, conducted in 2013 and 2018, found that the 
prevalence rate of tobacco smoking among the Saudi population was $12.2 \%$ and $21.4 \%$, respectively ${ }^{3,6}$. This increase of $9.2 \%$ in tobacco prevalence within only a five-year period may indicate a poor evaluation of the current tobacco issue.

Saudi college students have shown a higher rate of tobacco consumption than the general Saudi population. A systematic review and a meta-analysis study, conducted during 2010-2018, indicated that the smoking prevalence among Saudi college students was $17 \%$. The meta-analysis showed that the Saudi male smoking rate was $21 \%$ higher than the female rate $^{7}$. Another review stressed the importance of monitoring tobacco consumption among youth before it reaches a level of economic and healthcare burden ${ }^{8}$. Alotaibi et al. ${ }^{7}$ provided an epidemiological context about tobacco smoking prevalence among college students in the $\mathrm{KSA}^{7}$.

Additionally, ample studies have investigated various determinants associated with tobacco smoking among Saudi college students ${ }^{7-9}$. However, no systematic review has analyzed those determinants systematically. Thus, the purpose of this systematic review is to synthesize and to assimilate the vast amount of information available on the determinants of smoking by Saudi college students. The outcome of this review is to offer a foundation for specific recommendations concerning future research, theory, and interventions aimed at reducing Saudi college students' smoking behavior. Our research questions are:

a. What are the determinants/risk factors associated with tobacco smoking among Saudi college students?

b. Which study designs have been used to address the determinants of tobacco smoking?

c. Which theories (or models) have been previously used to explain students' smoking behavior?

d. What statistical analyses have been used to determine whether risk factors were associated with smoking?

\section{METHODS}

The study followed the Preferred Reporting Items for Systematic Review and Meta-Analyses (PRISMA) guidelines ${ }^{10}$. In this systematic review, the outcome of interest is tobacco smoking, which is defined as the inhalation of the smoke of burning cigarettes, cigars, and waterpipes. Smokeless tobacco and electronic cigarettes were excluded from the study, due to insufficient prior research of Saudi college students. Because we are interested in understanding the factors associated with smoking, we excluded studies that assessed factors associated with tobacco cessation or with secondhand smoking. In accordance with a previous study ${ }^{7}$, studies that recruited students from a college of medicine, pharmacy, applied health sciences, nursing, and/or dentistry were coded as health-related studies.

\section{Search strategy}

Two reviewers (SA and PD) independently searched for articles in four databases (i.e. PubMed, ProQuest, CINAHL, and Web of Science). These databases were selected due to either their comprehensiveness or their usage in previous research reviews ${ }^{7,8}$. The research was restricted to articles that were published between 2010 and 2019, in order to ensure the most up-to-date research studies of the topic. Key terms were established based on the objectives of this study and in accordance with the previous study ${ }^{7}$. Keywords were used to identify articles through the title or the abstract with no language restrictions (Supplementary file, Table S1). The investigators aimed to translate articles written in other languages (e.g. Arabic). Additional studies were added depending upon an investigation of each article's reference page or an online citation of included articles. The research ended on 30 August 2019.

\section{Inclusion and exclusion criteria}

Articles were included if they: 1) reported exclusively determinants of tobacco smoking, 2) focused on college students in the KSA, 3) were published between 2010 and 2019, and 4) measured tobacco smoking as a dependent variable (i.e. outcome). Articles were excluded if they: 1) were conducted outside of the KSA; 2) were reviews, commentaries, presentation posters, brief reports or graduate theses or dissertations; 3) measured e-cigarettes or smokeless tobacco use, 4) were not full-text or original research studies; 5) measured tobacco smoking as an independent variable (i.e. predictor); or 6) assessed tobacco cessation or secondhand smoking.

\section{Quality assessment}

All of the included articles were evaluated or appraised 
using the modified Reporting of Observational Studies in Epidemiology (STROBE) ${ }^{11,12}$. Any article that scored between $12-15,9-11$, or $0-8$ was considered to be of high, moderate, or low quality, respectively ${ }^{12}$. Two reviewers (SA and PD) separately scored each article. Then, they met to discuss any disagreement.

\section{Data extraction and data synthesis}

Using Excel software, two researchers (SA and PD) independently reviewed studies' titles and abstracts and extracted those that satisfied the inclusion criteria. After determining their final eligibility, fulltexts studies were imported into NVivo software for data extraction. From each article, two researchers independently gathered data for: the location of study, the year of study, the population of study, survey types, the sample size, the type of tobacco smoking, study design, the use of theories (Yes or No), the type of statistical tests, and the sampling techniques. Determinates that were tested with the outcome variable (i.e. tobacco smoking) were collected. Due to a huge variation of coding determinants among previous studies ${ }^{13,14}$, we coded any tested determinant into one of three categories: individual, social, or environmental levels. Those factors that concern an individual, such as demographic characteristics (e.g. age, gender etc.) or psychological wellbeing (e.g. stress and depression) are coded as an individual level. The social level encompasses any social connection or bond with the individual, such as friends and family. The environmental factors are those that mediate the structure of the surrounding community, such as a physical setting or place, policy, or media. Factors that showed significance at the $\mathrm{p} \leq 0.05$ level were emphasized in a table. This systematic review is IRB exempt and does not require approval.

\section{RESULTS}

\section{Characteristics of included studies}

Of the 300 studies, twenty-one met the inclusion criteria for this systematic review (Figure 1) ) $^{15-34}$. The characteristics of the included articles are presented in Table 1 . The majority ( $43 \%$ ) of studies investigated only male smoking behavior, while $38 \%$ and $19 \%$ of the included articles addressed risk factors of smoking among both genders and females, respectively. Almost half of the included studies were conducted among health-related students, either in the city of Riyadh or in the city of Jeddah. Moreover, $76 \%$ of the included studies combined waterpipe and cigarette smoking in their research as one term (i.e. tobacco smoking). Two studies investigated only cigarette smoking ${ }^{18,19}$ and one addressed waterpipe smoking ${ }^{27}$. Two research articles did not define which type of tobacco smoking was being measured ${ }^{20,29}$. Twenty studies examined the determinants of tobacco smoking among Saudi college students, using a retrospective cross-sectional design and based on no particular theoretical framework. However, one study did utilize a longitudinal observational design (time 1 vs time 2), using two theoretical frameworks (i.e. social learning theory and social control theory $)^{29}$. In all, $43 \%$ of the included studies utilized pre-designed questionnaires (Global Adults Tobacco Survey [GATS] or Global Youth Tobacco Survey [GYTS]). Despite the use of different sampling techniques (e.g. multi-stage sampling or random sampling) to recruit participants, 20 studies recruited participants from one campus. All of the included studies were written in English.

\section{Quality assessment}

The two authors (SA and PD) agreed on 298 items out of 315 with $94 \%$ agreement. The $6 \%(n=17)$ disagreement was resolved by further discussion. Overall, four studies maintained a high-quality score of 12 out of 15 points ${ }^{9,19,21,32}$. Seven studies showed a moderate quality of assessment, as they obtained a median score of $9^{15,18,20,23,29-31}$. Ten studies were rated as poor quality, with a median score of 7 (Supplementary file, Table S2) $)^{16,17,22,24-28,33,34}$.

\section{Determinants of tobacco smoking}

All but two studies found a range of risk factors that showed overall evidence for an association with tobacco smoking among Saudi college students. In our study, 21 risk factors were tested against the outcome variable (smoking behavior). Based on a bivariate analysis (i.e. the chi-squared test), 20 determinants were found significantly associated with Saudi tobacco smoking behavior, taking into consideration that some studies had tested more than one variable (Table 2 ). Seven studies indicated that some determinants were strong predictors of tobacco smoking among Saudi students, using multivariate analyses ${ }^{9,19,21,23,29,31,32}$. Although almost all of the included studies were done in a cross-sectional design, which inhibits the 
Table 1. Characteristics of included studies $(\mathrm{N}=21)$

\begin{tabular}{|c|c|c|c|c|c|c|c|}
\hline Authors (year) & $\begin{array}{l}\text { Gender of } \\
\text { population } \\
\text { (College) }\end{array}$ & Location & $\begin{array}{l}\text { Sample } \\
\text { sive }\end{array}$ & $\begin{array}{l}\text { Sample } \\
\text { technique }\end{array}$ & $\begin{array}{l}\text { Type of tobacco } \\
\text { smoking }\end{array}$ & Survey type & $\begin{array}{l}\text { Number } \\
\text { of factors } \\
\text { found } \\
\text { significant }\end{array}$ \\
\hline Mandil et al. ${ }^{9}$ (2011) & Both (All) & Riyadh & 6793 & Multi-stage & Cigarettes \& waterpipe & GYTS & 7 \\
\hline Abdulghani et al. ${ }^{15}$ (2013) & Female (AII) & Riyadh & 907 & Convenient & Cigarettes \& waterpipe & Self-developed & 0 \\
\hline $\begin{array}{l}\text { Al-Ghaneem and } \\
\text { Al-Nefisah }{ }^{16}(2016)\end{array}$ & $\begin{array}{l}\text { Male (Ed., Sci., } \\
\text { BA) }\end{array}$ & Majmaah & 301 & Multi-stage & $\begin{array}{l}\text { Cigarettes, waterpipe } \\
\text { \&t cigars }\end{array}$ & Not available & 1 \\
\hline Al-Haqwi et al. ${ }^{17}$ (2010) & $\begin{array}{l}\text { Both (Health: } \\
\text { Medical) }\end{array}$ & Riyadh & 215 & Convenient & Cigarettes \&t waterpipe & GATS & 2 \\
\hline Al-Kaabba et al. ${ }^{18}$ (2011) & $\begin{array}{l}\text { Both (Health: } \\
\text { Medical) }\end{array}$ & Riyadh & 153 & Convenient & Cigarettes & WHO & 2 \\
\hline Almogbel et al. ${ }^{19}$ (2013) & $\begin{array}{l}\text { Male (Three } \\
\text { campuses) }\end{array}$ & $\begin{array}{l}\text { Hassa \&t } \\
\text { Buraidah }\end{array}$ & 467 & Convenient & Cigarettes & Self-developed & 5 \\
\hline $\begin{array}{l}\text { Almohaithef and } \\
\text { Chandramohan }{ }^{20} \text { (2018) }\end{array}$ & Male (All) & Abha (KKU) & 337 & Multi-stage & Not available & Not available & 1 \\
\hline $\begin{array}{l}\text { Al-Mohamed and Amin }{ }^{21} \\
\text { (2010) }\end{array}$ & Male (All) & Hassa & 1382 & Multi-stage & Cigarettes \&t waterpipe & GYTS & 6 \\
\hline Alshehri et al..$^{22}$ (2019) & $\begin{array}{l}\text { Both (Health: } \\
\text { Medical) }\end{array}$ & Tabuk & 287 & Random & Cigarettes \&t waterpipe & Self-developed & 4 \\
\hline Almutairi'3 (2016) & Male (Ed., Sci.) & Riyadh & 715 & Convenient & Cigarettes \&t waterpipe & Self-developed & 4 \\
\hline Alswuailem et al. ${ }^{24}$ (2014) & Both (Health) & Riyadh & 400 & Convenient & Cigarettes \&t waterpipe & GATS & 4 \\
\hline $\begin{array}{l}\text { Ansari and Farooqi } i^{25} \\
(2017)\end{array}$ & $\begin{array}{l}\text { Female } \\
\text { (Health: } \\
\text { Medical) }\end{array}$ & Dammam & 332 & $\begin{array}{l}\text { Not } \\
\text { available }\end{array}$ & Cigarettes \& waterpipe & GYTS & 2 \\
\hline Ansari et al. ${ }^{26}$ (2016) & $\begin{array}{l}\text { Male (Health, } \\
\text { BA) }\end{array}$ & Majmaah & 340 & Multi-stage & Cigarettes \&t waterpipe & WHO & 1 \\
\hline Awan et al. ${ }^{27}$ (2016) & Male (Health) & Riyadh & 535 & $\begin{array}{l}\text { Random } \\
\text { Cluster }\end{array}$ & Waterpipe & Self-developed & 3 \\
\hline $\begin{array}{l}\text { Azhar and Alsayed }{ }^{28} \\
\text { (2012) }\end{array}$ & Female (All) & Jeddah & 310 & $\begin{array}{l}\text { Not } \\
\text { available }\end{array}$ & Cigarettes \& waterpipe & GATS & 1 \\
\hline Jiang et al. ${ }^{29}$ (2018) & Male (All) & Riyadh & 340 & $\begin{array}{l}\text { Random } \\
\text { Cluster }\end{array}$ & Not available & Self-developed & 3 \\
\hline Koura et al. ${ }^{30}$ (2011) & $\begin{array}{l}\text { Female (Lit., } \\
\text { Sci.) }\end{array}$ & Dammam & 1020 & Multi-stage & Cigarettes \& waterpipe & GYTS & 2 \\
\hline Mansour $^{31}$ (2017) & $\begin{array}{l}\text { Both (Health: } \\
\text { Dental) }\end{array}$ & Jeddah & 336 & Convenient & Cigarettes \&t waterpipe & Self-developed & 3 \\
\hline Mahfouz et al. ${ }^{32}$ (2014) & Both (All) & Jazan & 3764 & Multi-stage & Cigarettes \& waterpipe & GYTS & 3 \\
\hline Venkatesh et al. ${ }^{33}$ (2017) & Male (All) & Buraidah & 199 & Convenient & Cigarettes \& waterpipe & Self-developed & 0 \\
\hline Wali ${ }^{34}(2011)$ & $\begin{array}{l}\text { Both (Health: } \\
\text { Medical) }\end{array}$ & Jeddah & 643 & Convenient & Cigarettes \& waterpipe & GATS & 2 \\
\hline
\end{tabular}

conclusion of any findings, results identified some possible risk factors associated with tobacco smoking.

\section{Individual-level factors}

Thirteen risk factors were coded as individual-level determinants. These risk factors were age, belief, college affiliation, employment status, gender, income, knowledge, material status, religion, residence, school performance (i.e. Grade Point Average [GPA]), school year, and psychological issues (i.e. stress). Gender was the single risk factor that was found significant in all of the eight studies performing the chi-squared test $^{9,17,18,22,24,31,32,34}$. However, based on multivariate analyses (i.e. logistic regression), only Mansour ${ }^{31}$ 
Table 2. Determinants or risk factors examined by included studies

\begin{tabular}{|c|c|c|c|c|c|}
\hline \multirow[t]{2}{*}{ Theme } & \multirow[t]{2}{*}{ Factors } & \multirow{2}{*}{$\begin{array}{c}\text { Number } \\
\text { of } \\
\text { studies }\end{array}$} & \multicolumn{3}{|c|}{$\begin{array}{c}\text { Number of studies that found a statistically } \\
\text { significant association" }\end{array}$} \\
\hline & & & $\begin{array}{c}\chi^{2} \\
\text { [References] }\end{array}$ & $\begin{array}{l}\text { Logistic } \\
\text { regression } \\
\text { [References] }\end{array}$ & Direction \\
\hline \multirow[t]{13}{*}{ Individual } & Age & 9 & $2^{* *}[21,26]$ & $2[21,9]$ & $\begin{array}{l}\text { Older students had an association with } \\
\text { smoking. }\end{array}$ \\
\hline & Belief & 1 & $1[29]$ & $1[29]$ & $\begin{array}{l}\text { Non-smoking beliefs predict a change in the } \\
\text { smoking status. }\end{array}$ \\
\hline & College affiliation & 9 & $5[9,16,21,28,30]$ & 0 & $\begin{array}{l}\text { Non-health related students are associated } \\
\text { with smoking. }\end{array}$ \\
\hline & Employment & 1 & $1[20]$ & - & Unemployment is associated with smoking. \\
\hline & Gender & 8 & $\begin{array}{l}8[9,17,18,22,24 \\
31,32,34]\end{array}$ & $1[31]$ & $\begin{array}{l}\text { Being male is associated with smoking } \\
\text { behavior. }\end{array}$ \\
\hline & Income & 6 & $2[19,25]$ & 0 & High income is associated with smoking. \\
\hline & Knowledge & 5 & $4[22,23,31,34]$ & $2[23,31]$ & Low knowledge is linked to smoking status. \\
\hline & Material status & 6 & $1[9]$ & $1[9]$ & Being single is associated with smoking. \\
\hline & Religion & 2 & $1[23]$ & $1[23]$ & $\begin{array}{l}\text { Low Islamic practice is associated with smoking } \\
\text { behavior. }\end{array}$ \\
\hline & Residence & 4 & $1^{* *}[21]$ & $1[21]$ & Urban residence was a risk factor of smoking. \\
\hline & School performance & 5 & $1^{* *}[19]$ & $1[19]$ & Low GPA is associated with smoking. \\
\hline & School year & 10 & $4^{* *}[9,17,22,34]$ & 0 & $\begin{array}{l}\text { Senior students had an association with } \\
\text { smoking. }\end{array}$ \\
\hline & Psychological issues & 1 & $1[29]$ & 1 [29] & Stress is associated with tobacco smoking. \\
\hline \multirow[t]{6}{*}{ Social } & $\begin{array}{l}\text { Friends' substance } \\
\text { use }\end{array}$ & 1 & $1[32]$ & $1[32]$ & $\begin{array}{l}\text { Khat use (substance drug) is associated with } \\
\text { smoking. }\end{array}$ \\
\hline & $\begin{array}{l}\text { Teachers' smoking } \\
\text { status }\end{array}$ & 1 & 0 & - & - \\
\hline & Parents' education & 5 & $1[24]$ & - & $\begin{array}{l}\text { Students whose parents' education is college or } \\
\text { higher are associated with tobacco smoking. }\end{array}$ \\
\hline & $\begin{array}{l}\text { Family smoking } \\
\text { status }\end{array}$ & 8 & $\begin{array}{l}6[9,19,21,24,30, \\
31]\end{array}$ & $4[9,19,21,31]$ & $\begin{array}{l}\text { Any smoker in the family was a strong risk } \\
\text { factor for smoking. }\end{array}$ \\
\hline & Friends & 7 & $\begin{array}{l}7[9,18,19,21,23 \\
24,32]\end{array}$ & $\begin{array}{l}5 \\
{[9,19,21,23,32]}\end{array}$ & $\begin{array}{l}\text { Friends' smoking status was a strong risk factor } \\
\text { for smoking. }\end{array}$ \\
\hline & Family occupation & 2 & $1[18]$ & - & $\begin{array}{l}\text { Students whose mothers are working or retired } \\
\text { are associated with tobacco smoking. }\end{array}$ \\
\hline \multirow[t]{2}{*}{ Environmental } & Media & 1 & $1[21]$ & $1[21]$ & $\begin{array}{l}\text { Students who were exposed to anti-smoking } \\
\text { media messages were less likely to smoke. }\end{array}$ \\
\hline & Policy & 1 & $1[29]$ & $1[29]$ & $\begin{array}{l}\text { Government's efforts to control smoking was } \\
\text { associated with a decrease in smoking. }\end{array}$ \\
\hline
\end{tabular}

${ }^{*} p \leq 0.05$. ${ }^{*}$ Three articles $[21,25,27]$ tested one or all these factors but did not write them in the results section; thus, factors were not included.

found gender to be a statistically significant predictor of tobacco smoking among Saudi college current daily smokers ${ }^{31}$. Being male has statistically been shown to be associated with tobacco smoking among Saudi college students.

Out of nine studies using bivariate analysis, five reported that being enrolled in non-health related colleges was statistically associated with tobacco smoking $9,16,21,28,30$. However, all of the studies testing college affiliation did not retain their significance in multivariate analysis ${ }^{9,21}$. Moreover, age was tested in nine studies but showed significance in only two studies $^{21,26}$. In two multivariate analysis studies, older students were more likely to smoke than younger 
students $^{9,21}$. Four of five studies testing knowledge of the harmful effects of smoking found a significant relationship with tobacco smoking ${ }^{22,23,31,34}$. Only two studies indicated that having low knowledge of the side effects of smoking predicted smoking behavior among students ${ }^{23,31}$. Seven studies demonstrated a statistically significant relationship between smoking status and being single9, unemployment status $^{20}$, senior grade level ${ }^{9,17,22,34}$, low $\mathrm{GPA}^{19}$, urban residence $^{21}$, and psychological issues ${ }^{29}$. Jiang et al. ${ }^{29}$ tested two theories that did not show any significance, except for one construct (belief) of social control theory. College students who have a belief about non-smoking practices were significantly associated with a decrease in tobacco smoking ${ }^{29}$.

\section{Social-level factors}

Six risk factors (i.e. friends' substance abuse, teachers' smoking status, parents' education level, family smoking status, family occupational status, and friends' smoking status) were coded in the social level and were tested for an association with tobacco smoking. It was determined that college students whose friends are current smokers are more likely to be smokers ${ }^{9,18,19,21,23,24,32}$. Five of the seven studies showed that friends' smoking status predicted smoking behavior among Saudi college students $^{9,19,21,23,32}$. Moreover, the presence of any smoker in a family was associated with college students' smoking status ${ }^{9,19,21,24,30,31}$. In fact, four studies indicated that having any smokers in the family was a strong predictor for smoking among students ${ }^{9,19,21,31}$. An association between smoking status and students, whose friends use Khat (a substance drug) ${ }^{32}$, whose mothers are working or retired ${ }^{18}$, or whose parents are educated $^{24}$, was observed. Teachers' smoking status did not show any association with college students' smoking behavior ${ }^{18}$.

\section{Environmental-level factors}

Media and policy were the two factors coded as environmental level. Al-Mohamed and Amin ${ }^{21}$ reported, using bivariate and multivariate analyses, that exposure to high media messages of non-smoking served as a protective factor against smoking, among Saudi college students. Meanwhile, Jiang et al. ${ }^{29}$ indicated that governmental policies on controlling tobacco use predicted the change from smoking to non-smoking behavior.

Three studies displayed a statistical significance of a risk factor in a table; however, the authors neglected to report this in their results and discussion sections ${ }^{21,25,27}$. Thus, we did not include them as significant factors, as we assumed that they could be typographical errors. Awan et al. ${ }^{27}$ showed, in a table, that school year, age, and residence were significant, but they did not mention their significance in their article. Ansari and Farooqi ${ }^{25}$ and Al-Mohamed and Amin ${ }^{21}$ neglected to mention the significance of GPA and school year, respectively.

\section{DISCUSSION}

This systematic review is the first known attempt to synthesize the current literature on the determinants of tobacco smoking among college students in the KSA. This research sets a foundation for current and future research on tobacco smoking among Saudi college students. Although our study did not restrict itself to any specific research design, we found a lack of qualitative and other observational designs (e.g. experimental, case-control, or cohort) that could assist in better understanding some of the risk factors of tobacco smoking among Saudi college students. In fact, Mandil et al. ${ }^{9}$ and Almutairi ${ }^{23}$ recognized the importance of conducting rigorous qualitative studies in order to understand the dynamics of Saudi college students' smoking behavior. Moreover, our study discovered that there was poor utilization of theoretical frameworks to guide the research. Among the 21 included studies, there was only one study that utilized the social learning theory and the social control theory ${ }^{29}$. Theory-based research is needed to serve as a foundation for tobacco prevention and intervention programs ${ }^{14}$. Glanz and Bishop ${ }^{35}$ posit that, through the utilization of a theoretical framework, researchers will be able to understand both the determinants of health behavior and the process of health behavior change. Theory can guide research, can explain behavior, and can offer direction for designing and implementing interventions. In addition, all of the included studies relied heavily on retrospective methods of measuring tobacco smoking. Surveys are inclined to a number of biases and challenges, which could affect the results of the desirable outcome (studying smoking behavior). For example, several studies have found that self- 
reported measures of socially undesirable behaviors, such as smoking, are predisposed to underestimate the true amount smoked ${ }^{36}$, show digit bias (rounding to multiples of 5 or 10$)^{37}$, and are subject to recall bias $^{37}$. To minimize these biases, other collection methods of measuring tobacco smoking could take the form of prospective data collection, such as TimeLine Follow-Back (TLFB) ${ }^{37}$, ecological momentary assessment (EMA) $)^{37}$, or cigarette butt collection ${ }^{38}$. Finally, 20 studies recruited their participants either from one campus or from one college. Despite their sampling techniques (e.g. random or multistage sampling) within the campus or college, results could produce a limited application regarding their ability to be generalized to all Saudi university-age students. As of 2019, there are 30 universities, not including private institutions, distributed in different regions of the Kingdom ${ }^{39}$. Giving a snapshot of one campus or college is not necessarily representative of all KSA's higher education students ${ }^{40}$. Therefore, future research should attempt to recruit participants randomly from different institutions in the KSA. A final observation is that the majority of articles in the literature $(n=16)$ did not make a clear distinction between cigarette smoking and waterpipe smoking, especially when measuring cognitive factors such as perceptions, beliefs, attitudes, or knowledge. Some college students may believe that using a waterpipe is less harmful than smoking a cigarette ${ }^{41}$.

\section{Risk factors of tobacco smoking}

A basic tenet of understanding tobacco smoking among Saudis is to understand the underlying risk factors that contribute to the smoking problems. It has been argued that preventing youth from starting will reduce their chances of becoming smokers later in life ${ }^{14}$. The included studies tested many risk factors thought to be associated with Saudi students' tobacco smoking. There were many more individual factors tested for an association with Saudi college students' tobacco smoking than any other social or environmental factors. However, our study found that only four dominant risk factors (college affiliation, gender, knowledge, and school year) were statistically associated with Saudi students' smoking, in four or more studies. Being male was found statistically related to smoking in all studies testing the gender variable. A notable explanation of the gender difference is that Saudi male college students could have fewer social restrictions than females. Saudi men enjoy social freedoms, such as being able to purchase tobacco and smoke publicly, whereas women are socially discouraged from doing so.

The family's smoking status and friends' smoking status were the major two social factors that showed a statistical relationship in smoking behavior, in six or more studies. Environmental factors were the least tested for an association with tobacco smoking, and were indicated in only two studies ${ }^{21,29}$. A noteworthy finding is that exposure to media messages related to non-smoking or to implementing a policy to control smoking was significant enough to influence Saudi students' decision to maintain their non-smoking status or to change their smoking behavior, respectively ${ }^{21,29}$. Moreover, having a strong belief in non-smoking or practicing the Islamic faith produced significant evidence with changes in smoking behavior among Saudi university students $^{23,29}$. Finally, friends' substance abuse (Khat) was found to be a strong predictor of smoking tobacco among southern university students in the $\mathrm{KSA}^{32}$.

\section{Limitations}

Due to an enormous variation in data collection, study design, sample size, study population, and/or age groups among the included studies, we cannot conclude a causal relationship between these factors and smoking among Saudi university students, nor can we generalize the findings. Instead, we infer that some individual factors and social factors could play a role in influencing Saudi students' smoking behavior given the data. Although the majority of included articles $(n=16)$ categorized both cigarette and waterpipe smoking as 'tobacco smoking' in their research, special attention should be paid to the degree to which tobacco smoking (cigarette vs waterpipe) is more associated with each factor. Another limitation is that the search produced only articles published in English and in selected databases. Thus, we may have missed other studies that were published in other languages (e.g. Arabic) and were in other databases.

\section{CONCLUSIONS}

Four of the individual-level and two of social factors were able to demonstrate the association between 
college students and tobacco smoking. To better understand the current problem, future research should address Saudi students' smoking behavior using other research methodologies (experiment or prospective observational) or using theoretical models to explain Saudi smoking behavior. Utilizing theoretical models as described above could assist in the development of intervention programs. Moreover, researchers should test other measuring approaches (TLFB or EMA ${ }^{37}$ ) to avoid certain biases and to arrive at an accurate estimate of tobacco smoking. More importantly, future research should make a clear definition and designation between cigarette and waterpipe smoking when measuring the association of certain factors (e.g. perceptions or knowledge), because the degree of each factor (e.g. knowledge) about tobacco could be different between cigarette smokers and waterpipe users ${ }^{41}$. Furthermore, we encourage future research to explore possible risk factors such as social, economic, environmental, biological, and physiological influences that may predict smoking behavior among Saudi college students.

\section{REFERENCES}

1. Drope J, Schluger N, Cahn Z, et al. The Tobacco Atlas. 6th ed. Atlanta, GA: American Cancer Society, Vital Strategies; 2018. https://tobaccoatlas.org/wp-content/ uploads/2018/03/TobaccoAtlas_6thEdition_LoRes_ Rev0318.pdf. Accessed March 12, 2020.

2. Centers for Disease Control and Prevention. Smoking is down but almost American adults still smoke. https:// www.cdc.gov/media/releases/2018/p0118-smokingrates-declining.html. Published January 18, 2018. Accessed August 15, 2019.

3. Moradi-Lakeh M, El Bcheraoui C, Tuffaha M, Daoud F, Al Saeedi M, Basulaiman M, et al. Tobacco consumption in the Kingdom of Saudi Arabia, 2013: Findings from a national survey. BMC Public Health. 2015;15(1):611621. doi:10.1186/s12889-015-1902-3

4. Alrabah M, Gamaleddin I, Allohidan F. International approaches to tobacco-use cessation programs and policy for adolescents and young adults in Saudi Arabia. Curr Addict Rep. 2018;5(1):65-71. doi:10.1007/s40429-0180188-9

5. AlBedah AM, Khalil MK. The economic costs of tobacco consumption in the Kingdom of Saudi Arabia. Tob Control. 2014;23(5):434-436. doi:10.1136/ tobaccocontrol-2012-050665

6. Algabbani AM, Almubark R, Althumiri N, Alqahtani A, BinDhim N. The prevalence of cigarette smoking in Saudi Arabia in 2018. FDRJ. 2018;1(1):1-13. doi:10.32868/rsj. v1i1.22

7. Alotaibi SA, Alsuliman MA, Durgampudi PK. Smoking tobacco prevalence among college students in the Kingdom of Saudi Arabia: Systematic review and meta-analysis. Tob Induc Dis. 2019;17(April). doi:doi:10.18332/tid/105843

8. Almutairi KM. Smoking among Saudi students: a review of risk factors and early intentions of smoking. J Community Health. 2014;39(5):901-907. doi:10.1007/s10900-014-9909-8

9. Mandil A, BinSaeed A, Ahmad S, Al-Dabbagh R, Alsaadi M, Khan M. Smoking among university students: a gender analysis. J Infect Public Health. 2010;3(4):179-187. doi:10.1016/j.jiph.2010.10.003

10. Moher D, Liberati A, Tetzlaff J, Altman FG. Preferred repotting items for systematic review and meta-analyses: the PRISMA statement. Int J Surg. 2010;8(5):336-341. doi:10.1016/j.ijsu.2010.02.007

11. Von Elm E, Altman DG, Egger M, et al. The strengthening the reporting of observational studies in epidemiology (STROBE) statement: Guidelines for reporting observational studies. Prev Med. 2007;45(4):247-251. doi:10.1016/j.ypmed.2007.08.012

12. Alemu BT, Olayinka O, Baydoun HA, Hoch M, AkpinarElci, M. Neonatal hypoglycemia in diabetic mothers: A systematic review. Curr Pediatr Res. 2017;21(1):42-53. https://www.alliedacademies.org/articles/neonatalhypoglycemia-in-diabetic-mothers-a-systematic-review. pdf. Accessed March 12, 2020.

13. Dadipoor S, Kok G, Aghamolaei T, Heyrani A, Ghaffari M, Ghanbarnezhad A. Factors associated with hookah smoking among women: A systematic review. Tob Prev Cessation. 2019;5(August). doi:10.18332/tpc/110586

14. Tyas SL, Pederson LL. Psychosocial factors related to adolescent smoking: a critical review of the literature. Tob Control. 1998;7(4);409-420. doi:10.1136/tc.7.4.409

15. Abdulghani HM, Alrowais NA, Alhaqwi AI, et al. Cigarette smoking among female students in five medical and nonmedical colleges. Int J Gen Med. 2013;6:719-727. doi:10.2147/ijgm.s48630

16. Al-Ghaneem SG, Al-Nefisah OS. The prevalence of smoking among male students of Majmaah University, KSA. J Taibah Univ Med Sci. 2016;11(2):175-178. doi:10.1016/j.jtumed.2016.01.006

17. Al-Haqwi AI, Tamim H, Asery A. Knowledge, attitude and practice of tobacco smoking by medical students in Riyadh, Saudi Arabia. Ann Thorac Med. 2010;5(3):145148. doi:10.4103/1817-1737.65044

18. Al-Kaabba AF, Saeed AA, Abdalla AM, Hassan HA, Mustafa AA. Prevalence and associated factors of cigarette smoking among medical students at King Fahad Medical City in Riyadh of Saudi Arabia. J Family Community Med. 2011;18(1):8-12. doi:10.4103/1319-1683.78631

19. Almogbel YS, Abughosh SM, Almogbel FS, Alhaidar IA, Sansgiry SS. Predictors of smoking among male 
college students in Saudi Arabia. East Mediterr Health J. 2013;19(11):909-914. doi:10.26719/2013.19.11.909

20. Al-Mohaithef M, Chandramohan S. Prevalence of smoking and its associated factors among male college students in Abha, Kingdom of Saudi Arabia: A cross-sectional study. Int J Med Res Health Sci. 2018;7(4):35-41. https:// www.ijmrhs.com/medical-research/prevalence-ofsmoking-and-its-associated-factors-among-male-collegestudents-in-abha-kingdom-of-saudi-arabia-a-crosssect. pdf. Accessed March 12, 2020.

21. Al-Mohamed HI, Amin TT. Pattern and prevalence of smoking among students at King Faisal University, Al Hassa, Saudi Arabia. East Mediterr Health J. 2010;16(1):56-64. doi:10.26719/2010.16.1.56

22. Alshehri RA, Alwakeel AA, Alatawi OA, Albalwi AM, Alsubaie AT, et al. Pattern, knowledge, and attitude of smoking among medical students in Saudi Arabia. IJMDC. 2019;3(5):441-445. doi:10.24911/ IJMDC.51-1546557742

23. Almutairi KM. Predicting relationship of smoking behavior among male Saudi Arabian college students related to their religious practice. J Relig Health. 2016;55(2):469479. doi:10.1007/s10943-015-0003-z

24. AlSwuailem AS, AlShehri, MK, Al-Sadhan A. Smoking among dental students at King Saud University: Consumption patterns and risk factors. Saudi Dent J. 2014;26(3):88-95. doi:10.1016/j.sdentj.2014.03.003

25. Ansari K, Farooqi FA. Comparison and prevalence of smoking among Saudi females from different departments of the college of applied medical sciences in Dammam. Int J Health Sci. 2017;11(5):56-62. PMID:29114195.

26. Ansari T, Alghamdi T, Alzahrani M, et al. Risky health behaviors among students in Majmaah University, Kingdom of Saudi Arabia. J Family Community Med. 2016;23(3):133-139. doi:10.4103/2230-8229.189105

27. Awan KH, Alrshedan A, Al Kahtani M, Patil S. Waterpipe smoking among health sciences university students: Knowledge, attitude and patterns of use. Saudi Dent J. 2016;28(4):189-193. doi:10.1016/j.sdentj.2016.05.001

28. Azhar A, Alsayed N. Prevalence of smoking among female medical students in Saudi Arabia. Asian Pac J Cancer Prev. 2012;13(9):4245-4248. doi:10.7314/apjcp.2012.13.9.4245

29. Jiang G, Aldamer S, Bendania A. Smoking behaviour among male students in a Saudi University. East Mediterr Health J. 2018;24(5):411-418. doi:10.26719/2018.24.5.411

30. Koura MR, Al-Dossary AF, Bahnassy AA. Smoking pattern among female college students in Dammam, Saudi Arabia. J Family Community Med. 2011;18(2):63-68. doi:10.4103/2230-8229.83370

31. Mansour AY. Predictors of Smoking among Saudi Dental Students in Jeddah. Am J Health Behav. 2017;41(3):329337. doi:10.5993/AJHB.41.3.12

32. Mahfouz MS, Alsanosy RM, Gaffar AM, Makeen A.
Tobacco use among university students of Jazan Region: Gender differences and associated factors. BioMed Res Int. 2014;2014:1-7. doi:10.1155/2014/279231

33. Venkatesh E, Al Jemal MY, Al Samani AS. Characteristics, reasons, behavior and knowledge towards waterpipe smoking in Saudi Arabia. Int J Adolesc Med Health. 2017;20170090. doi:10.1515/ijamh-2017-0090

34. Wali SO. Smoking habits among medical students in Western Saudi Arabia. Saudi Med J. 2011;32(8):843-848. PMID:21858395.

35. Glanz K, Bishop DB. The role of behavioral science theory in development and implementation of public health interventions. Annu Rev Public Health. 2010;31(1):399418. doi:10.1146/annurev.publhealth.012809.103604

36. Gorber SC, Schofield-Hurwitz S, Hardt J, Levasseur G, Tremblay M. The accuracy of self-reported smoking: a systematic review of the relationship between selfreported and cotinine-assessed smoking status. Nicotine Tob Res. 2009;11(1):12-24. doi:10.1093/ntr/ntn010

37. Shiffman S. How many cigarettes did you smoke? Assessing cigarette consumption by global report, TimeLine Follow-Back, and ecological momentary assessment. Health Psychology. 2009;28(5):519-526. doi:10.1037/ a0015197

38. Blank MD, Breland AB, Enlow PT, Duncan C, Metzger A, Cobb, CO. Measurement of smoking behavior: Comparison of self-reports, returned cigarette butts, and toxicant levels. Exp Clin Psychopharmacol. 2016;24(5):348-355. doi:10.1037/pha0000083

39. Saudi Arabia Ministry of Education. State Universities (introduction). https://www.moe.gov.sa/en/ HigherEducation/governmenthighereducation/ StateUniversities/Pages/Introduction.aspx. Published June 24, 2019. Accessed October 15, 2019.

40. Martínez-Mesa J, González-Chica DA, Duquia RP, Bonamigo RR, Bastos JL. Sampling: how to select participants in my research study?. An Bras Dermatol. 2016;91(3):326-330. doi:10.1590/abd18064841.20165254

41. Creamer MR, Loukas A, Li X, et al. College students' perceptions and knowledge of hookah use. Drug Alcohol Depend. 2016;168:191-195. doi:10.1016/j.drugalcdep.2016.09.004

\section{CONFLICTS OF INTEREST}

The authors have completed and submitted the ICMJE Form for Disclosure of Potential Conflicts of Interest and none was reported.

FUNDING

There was no source of funding for this research.

PROVENANCE AND PEER REVIEW

Not commissioned; externally peer reviewed. 